\title{
NOTAS GONGORINAS
}

I

Hermana Marica...

\author{
Hermana Marica, \\ mañana, que es fiesta, \\ no irás tú a la amiga \\ ni iré yo a la escuela. \\ Pondraste el corpiño \\ y la saya buena, \\ cabezón labrado, \\ toca y albanega; \\ y a mí me pondrán \\ mi camisa nueva, \\ sallo de palmilla, \\ media de estameña... [etc.].
}

Esste romancillo gongorino, siempre citado con elogio, es -al mismo tiempo- ejemplo corriente cuando se habla de lo no muy común en el poeta. "Sencillez y naturalidad - escribió Dámaso Alonso- sólo se encuentran en tres o cuatro composiciones de Góngora: Hermana Marica, La más bella niña, etc... (si bien -aclara- cuando Góngora escribía estas composiciones, también escribía poesías "cultas" y complicadas) ${ }^{1}$. Por su parte, Pedro Henríquez Ureña es aún más radical, cuando considera que Hermana Marica es la única poesía no cultista de Góngora: "Una vez se apartará (Góngora) del estilo culterano: en Hermana Marica, portento de transfusión, en que el poeta habla desde dentro del niño...» ${ }^{2}$. Quizá pueda defenderse la sencillez de otras composiciones

1 DÁmaso Alonso, La lengua poética de Góngora, Madrid, I935, pág. 37.

2 Pedro Henrfouez UREÑa, prólogo a Góngora. Romances y Letrillas, ed. de Buenos Aires, 1939, pág. 8. En su antología titulada Cien de las mejores poesias castellanas (ed. de Buenos Aires, 1946, págs. I I2-130) incluye un romancillo, una letrilla, dos sonetos y la Fábula de Polifemo y Galatea. El romancillo es Lloraba la niña, y no Hermana Marica. 
gongorinas fuera de las citadas, aparte de quehay grados difíciles de reducir a dos sectores definidos. Pero, restringiéndonos a Hermana Marica, no cabe duda de que es ejemplo inevitable y rotundo, con el agregado de su carácter singular $y$, no menos, personalísimo.

La, en general, precisa cronología de las poesías de Góngora nos dice que se trata de una composición juvenil, de $1580^{1}$. Pero sabemos hoy que tal situación poco significa en la trayectoria del poeta. No existen dos Góngoras cortados por una línea transversal, sino una línea longitudinal que abarca todā su obra. De ahí que, ya por la época en que Góngora escribe'Hermana Marica, escribe también composiciones típicamente cultistas. (Dámaso Alonso destaca que del mismo año, I580, es la poesia De aLos Lusiadas» de Luis de Camoens, que tradujo Luis de Tapia...)

Sin llegar al exclusivismo de Pedro Henríquez Ureña, es indudable que esta poesía resalta de manera nítida. $Y$ también podemos explicar la actitud psicológica que determinó aquí, de manera ineludible, la especial «naturalidad del poema. Góngora se identifica con el niño, y sería aberración hablar "cultamente» desde dentro del niño. Actitud que se refuerza al considerar que fue esa la única vez que Góngora afloró a través del niño.

Aclaro, además, que si bien es raro en la lírica de nuestro poeta esta actitud (infantil», Góngora no h ace, en esto, sino colocarse en lo que era entonces corriente. La literatura de la época raramente toca el tema del niño: los pícaros son niños sólo en apariencia, y lo mismo ocurre con los que aparecen en La Numancia de Cervantes y en comedias de Lope. Por otro lado, el niño como público sólo parece ser tenido en cuenta a través de cuentos y canciones de transmisión oral ${ }^{2}$. Por eso, y por sus méritos propios, la poesía de Góngora constituye un raro, un particular ejemplo.

La belleza de este romancillo surge de su desarrollo directo, de su lengua infantil, de su comprimida y -al mismo tiempo- amplia visión del mundo del niño y su día de fiesta visto como futuro (fiesta y holganza; plan del día; vestidos, dulces, juegos; los amigos, los cantos...). $Y$,

1 Según fecha contenida en el Manuscrito Chacón. Ver Lư'S DE GóngorA, Obras poéticas, I, Nueva York, I921. ed. de R. Foulché-Del,BOSC. [y AxFonso REYEs], pág. 8. En el manuscrito Chacón Hermana Marica figura en el tomo segundo, pág. 265. El romancillo se imprimió por primera vez en las Obras en verso del Homero español que recogió JUAN LóPEZ DE VICUÑa. Madrid, I627.

2 En realidad, el niño como tema (salvo el sector especial de los cuentos y canciones) es un producto moderno. Nace en el siglo xIX y se afirma - si cabe- en nuestro siglo. En forma paralela, el niño como público, en pasados siglos, aprende leyendas, cuentos y canciones, oralmente. Este es, en rigor, su «libro» literario. 
a manera de travieso y algo apicarado fin, la mención de Barbola y tlas bellaquerias».

No cabe duda de que ese final altera un tanto el perfil del poema, pero, dicho en la forma en que lo dice Góngora, el contraste (si se puede hablar de contraste) se empina sobre un travieso mohín y apenas aludidos episodios:

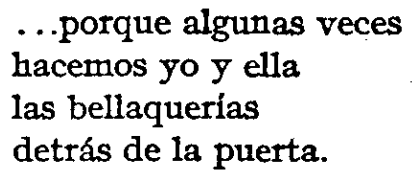

Este final está visto más desde la psicología del hombre (según Dámaso Alonso, entra ya "en lo malicioso") ${ }^{1}$. Sin embargo, lo visible es que, sin desentonar, agrega un nuevo y desusado matiz, y remata, con perfil de niño crecido, graciosamente el poema. Algo más conviene agregar. Sabemos que se trata de un poema juvenil escrito por Góngora poco antes de cumplir los veinte años. No muy lejos de una vivida experiencia personal pudo recordar en sus versos episodios de su propia infancia y -al mismo tiempo- poner en los versos finales un regusto picaresco, reflejo del adolescente o del mozo, más que del niño. Sin embargo, la acomodación está igualmente lograda.

En fin, el llamativo final hasta puede medirse, comparativamente, con derivaciones inmediatas del romancillo, que exageran $\mathrm{y}$, por tanto, rompen el encanto especial del romance gongorino. Pensemos en $\mathrm{Her}-$ mano Perico:

$$
\begin{aligned}
& \text {...habrá boda y fiesta, } \\
& \text { dormiremos juntos } \\
& \text { en cama de seda, } \\
& \text { y haremos un niño } \\
& \text { que vaya a la escuela. }
\end{aligned}
$$

Cronologia

La hoy, en general, bien conocida cronología de los textos gongorinos (cronología cuya base está, indudablemente, en Foulché-Delbosc y A1fonso Reyes, a través del famoso manuscrito Chacón) permite afirmar que este romancillo corresponde a un momento inicial, como que fue escrito en 580 . La fecha tiene en Hermana Marica el valor común de fijar un origen, y no, como se afirmaba en otra época y con composicio-

1 Cf. Dámaso Alonso, Góngora y el Polifemo, I, Madrid, I961, pág. 95. 
nes de este tipo, el valor capital de contribuir a marcar una de las dos etapas que se defendía en Góngora ( $\mathbb{E} 1$ Príncipe de la Luz» y «El Príncipe de Tinieblas", etc.).

Fuera de tales planteos, hoy vemos que el conocimiento de la fecha tiene importancia notoria en cuanto - aparte los «dos» Góngoras- nos permite desechar falsos orígenes o derivaciones.

Efectivamente, en el conocido Entremés de los romances, tan traído y llevado en los últimos años en relación a una posible fuente cervantina, se menciona un romance que tiene claro parentesco con el romancillo de Góngora. Es el romance que comienza:

$$
\begin{aligned}
& \text { Hermano Perico } \\
& \text { que estás a la puerta } \\
& \text { con camisa limpia } \\
& \text { y montera nueva... }
\end{aligned}
$$

y cuya estructura general guarda también paralelismo estrecho con el romance de Góngora.

Menéndez y Pelayo, al estudiar el Entremés de los romances, recordaba que, en éste, se menciona el romancillo de Góngora La más bella niña/ de muestro lugar... Y, posteriormente, dice: "Repítese aquel antiguo romance que sirvió más tarde de modelo a Góngoran:

$$
\begin{aligned}
& \text { Hermano Perico } \\
& \text { que estás a la puerta } \\
& \text { con camisa limpia } \\
& \text { y montera nueva... }
\end{aligned}
$$

«Este lindísimo romance -concluye-, de autor anónimo, que debió ser muy popular en Castilla, cierra, por decirlo aś, la primera parte de este pequeño draman. 2

Como Menéndez y Pelayo no tuvo a su alcance una cronología rigúrosa de las poesías gongorinás y como sin duda partió de la sospecha, tan frecuente, que considera el romance anónimo anterior al romance firmado, de ahí dedujo que el romance anónimo fue el modelo del de Góngora. Hoy sabemos que el romance de Góngora es anterior y - claro está- base induabable del otro.

Por lo pronto, el romance anónimo figura, por primera vez, en el

1 Cf. Entremés de los Romances (en Cenvantes [?], Varias obras inéditas publicadas por ADOLFO DE CASTRO. Madrid, 1874, pág. I5I.

2 MENGNDEZ Y PELAYo, Estudios de critica histórica y literaria, I, Buenos Aires, 1944, págs. 282-283. 
Romancero general (I600-I604-I605). Alli también está incluida la poesía de Góngora La más bella niña ${ }^{1}$. Es decir, dos de las poesías citadas cercanamente en el Entremés de los romances.

Menéndez Pidal, que defiende (junto a Millé y Giménez y otros) la idea de que el Entremés de los romances es anterior al Quijote y posible estimulo de éste, sospecha que "el entremés debió de ser escrito en I59I o poco después; quiere burlarse de la excesiva boga de los Romanceros, que sin cesar se reeditaban desde hacía medio siglo, y en especial del Romancero intitulado Flor de Romances, que se venía publicando y añadiendo desde I59I a I597" 2 .

Aún más; las principales razones en que Menéndez Pidal apoya la posible fecha del Entremés se apoyan en el romance Hermano Perico, por las alusiones a Drake, los ingleses y los luteranos que aparecen en él.

Mi hermano Bartolo
se va a Inglaterra
a matar al Draque
y a prender la Reina,
y a los luteranos
de la Brandonesa.
Tiene de traerme
a mi de la guerra
un luteranico
con una cadena,
y una luterana
a señora agüela...

En fin, no nos interesa aquí la fecha del Entremés en relación al Quijote, sino en relación al romancillo de Góngora, y, la verdad, aunque aceptáramos la fecha extrema inferior, de I59I, bien visto está que la composición de Góngora es anterior.

Lo que la rotunda prueba de las fechas muestra se confirma con el análisis de la estructura y la elaboración de los romancillos. Sin pretender una demostración absoluta (casi imposible en estos problemas), el romancillo anónimo tiene todo el carácter de una parodia, cuya acentuación se marca - si cabe- en el final. Vale decir, producto inspirado y derivado de la composición gongorina. Eso sí, no creo que el romance anóni-

1 Ver Romancero general (I600, I604, I605), ed. de A. GonZÁx.EZ PALENCIA. I. Madrid, 1947. No figura en esta colección Hermana Marica, aunque sí se encuentran en ella numerosos romances de Góngora.

2 RAMón MENÉNDez PIDAL, Un aspecto de la elaboración del "Quijote" (en De Cervantes y Lope de Vega. Buenos Aires, '1940, pág. 20. Cf., también, págs. 54-55). 
mo sea también obra de Góngorà, como sospechan Juan Millé y Giménez y Angel González Palencia 1.

Si, Hermana Marica debió ser, desde temprano, muy difundida obrilla y factor importante en la temprana popularidad de Góngora. Por lo pronto, éste lo destaca exclusivamente en otro romancillo, poco posterior (de 1587 ), también muy difundido. Es el romancillo que comienza:

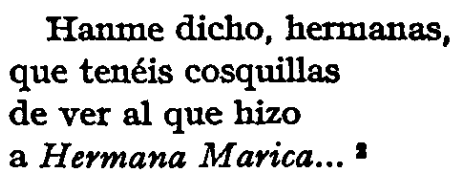

Ia descendencia inmediata de Hermana Marica no se reduce sólo a Hermano Perico, si bien éste tuvo, por su cuenta, mucha difusión. El Romancero general incluye otro romance, Hermana Juanilla, que pertenece a la familia. Estos son los primeros versos:

Hermana Juanilla,
entremos a cuenta,
dime ¿quién te dio
esa saya nueva?...

Claro que aquí cabe tanto la posibilidad de que este último romancillo proceda del poema de Góngora o del Hérmano Perico... O, quizá, de un recuerdo conjunto de los dos. De todos modos, el valor del tercero supone un descenso, aun considerado únicamente en relación a Hermano Perico.

Resonancias

El reconocible encanto del romancillo de Góngora (encanto en el que entra, por supuesto, el atrevido final) no se cierra con los años del poeta

1 Ver "Indice de primeros versos»: —Hermano Perico, 82 (¿Góngora?)..." (Romancero general. II, ed. de Madrid, 1947, pág. 38r). Juan Millé y Giménez, Sobre la génesis del 'Quifote', Barcelona, 1930, págs. 94-95.

2 Cf. GÓNGORA, Romances y letrillas, pág. 54. Más adelante dice:

$$
\begin{aligned}
& \text {..compone romances } \\
& \text { que cantan y estiman } \\
& \text { los que cardan paños } \\
& \text { y ovejas esquilan... (pág. 59). }
\end{aligned}
$$

Sin dar demasiada importancia a estos versos, la verdad que convienen a $\mathrm{Her-}$ mana Marica.

3 Romancero general, II, Ed. de Madrid, 1947, págs. I2-13. 
ni con la descendencia que le nació al poema en el siglo xvir. Por el contrario, el romancillo fue sostén firme del prestigio de Góngora cuando en los siglos XVIII y XIX era corriente distinguir entre los "dos Góngoras» (el claro y el oscuro, el malo y el bueno). Se elogiaban entonces las poesías más claras y se combatían las más complejas y "cultas». Dentro de tal ámbito, Hermana Marica era citada frecuentemente como defensa de las virtudes poéticas de su autor, aunque fuera lugar común dolerse del ingenio extraviado de Góngora.

Eso sí, sospechamos que el romancillo corrió a menudo con su final amputado. Creo que, por ejemplo, de esta manera lo conoció el padre Sarmiento en el siglo XVIIr, cuando escribe: "A este tenor trahe Góngora un coloquio pueril entre dos hermanitos, Perico [sic] y Marica, y es el más natural y sencillo que se puede imaginar. Es el Romance nono de los burlescos, y comienza:

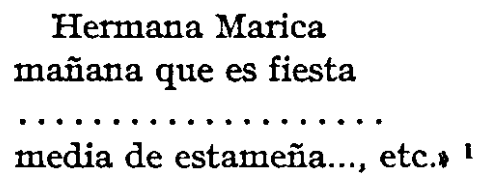

No sé de dónde sacó el nombre Perico (¿figuraba en una versión del romancillo, o hay confusión con Hermano Perico?). No sé, pero el breve análisis del párrafo del padre Sarmiento permite sospechar que la poesía circulaba entonces trunca. $Y, \sin$ ir muy lejos, recuerdo haber leído (creo que en Alfonso Reyes) que Menéndez y Pelayo alguna vez citó el romancillo sin los versos finales. Lo que sí puedo decir también es que Hermana Marica no figura en la versión definitiva de Las cien mejores poesias [líricas] de la lengua castellana ${ }^{2}$.

Ya en nuestro siglo Azorín escribió una de sus breves recreaciones "al margen de los clásicos», que tituló Las bellaquerias. Un pcema como Hermana Marica parece repugnar este tipo de comentario, como si la gracia y lograda naturalidad se rompieran fuera de los ya logrados versos de Góngora. De ahí que los párrafos de Azorín nos patezcan redundantes. Tiene el fino escritor español mejores ejemplos en esta dirección ${ }^{3}$.

1 P. Sarminento. Memoria, I, Madrid, I775, pág. 194.

2 Cf. MENGNDEZ y PELAYo, Las cien mejores poesias de la Lengua castellana, ed. de Buenos Aires, 1948. Figuran aquil cinco poesias: Angélica y Medoro, Servia en Orán al rey, Entre los sueltos caballos, Ande yo caliente y La más bella niña.

3 Azorín tecuerda la poesía con el título La vida del muchacho (así se la conocja), título quizá más exacto, pero menos feliz. Se publicó por primera vez en la revista Helios, de Madrid, 1903, I, núm. 3, pág. $35^{8}$ (Una impresión de Góngora; Las bellaquerias). Fue recogida en libro en $A l$ margen de los clásicos [1914] (ver Obras completas, III, Madrid, 1947, págs. 203-204). 
Más cerca a nuestros días y en América dos poemas de dos buenos poetas hispanoamericanos nos llevan al ámbito inconfundible del romancillo gongorino. Uno es de Jacinto Fombona Pachano; el otro, de Bernardo Ortiz de Montellano:
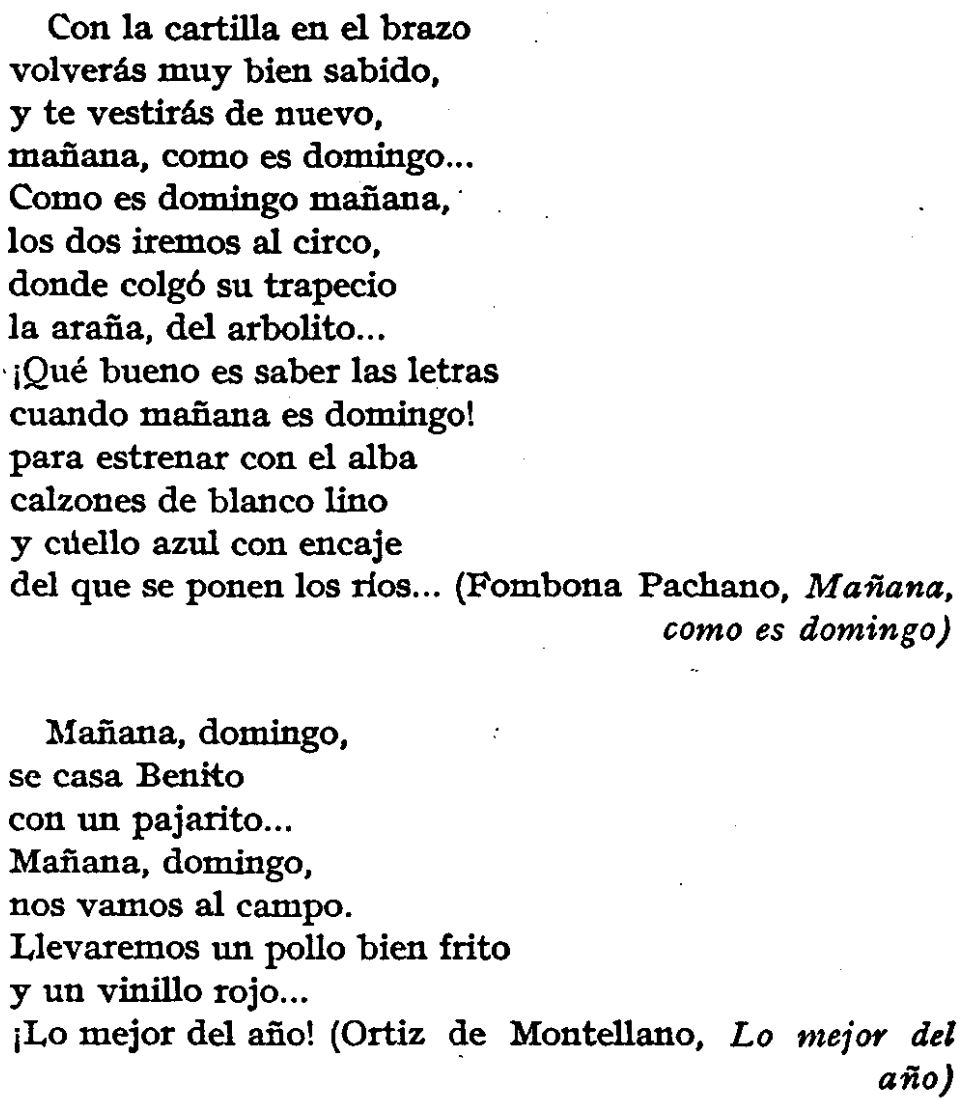

Creo que en los dos casos (y con respecto al romancillo de Góngora) hay un evidente aire de familia. Más acentuado en el primero, aunque visible también en el segundo, a pesar de coplas populares (que ya permitía Góngora en su poesía), variantes y «modernizaciones». He querido cerrar con esta referencia a dos poetas hispanoamericanos de nuestro siglo el breve estudio del famoso romancillo de Góngora.

Sin ninguna sorpresa, el romancillo atestigua - ¿hay alguna duda? la capacidad poética del autor, imponente en su atrevida y revolucionaria "forma", pero no menos grande cuando pretende mostrarla - iy tanto! en la poesía transparente y sencilla, en una composición que, como Hermana Marica, está a un lado de los cambios estéticos y las luchas de escuela. En fin, como recordaba aquel fino catador que era Alfonso Reyes, no conviene olvidar este sector de Góngora, menos espectacular, menos 
imitado quizá (menos atacado también), pero que revela igualmente los altos dones del poeta 1.

Hermana Marica, con su frescura que atraviesa los siglos, con su fecundidad que -como vemos- llega hasta poetas de nuestra época, muestra que Góngora sobrevive con y $\sin$ el gongorismo. De nuevo, don de la poesía.

II

Pacer y pisar estrellas...

Góngora pertenece al grupo que forman unos pocos poetas, cuyas bellezas, novedades y problemas los mantienen en un primer plano indudable. Podrán pasar entusíasmos desbordados, podrán sucederse tendencias y escuelas, pero no cabe duda de que Góngora ha adquirido, desde hace años, un valor de permanencia. Góngora es hoy menos escándalo y más remansada, accesible poesía. Aún es socorro frecuente - fecundidad, estímulode muchos poetas y, sobre todo, tema inagotable de disquisiciones críticas.

En esta última dirección es justo decir que pocos, como Góngora, nos ofrecen un mayor caudal de análisis: obra total, poema, verso, metáfora, vocablo..., etc.; mucho queda todavía por dilucidar en la prieta urdimbre de la poesía gongorina. Particularmente, en los muchos versos que viven en nuestra memoria por el rotundo acierto de su ritmo, de su música, de su color, o, más bien, por la maciza unidad de todos estos elementos.

Decía Quintana, a propósito de Quevedo: «De nadie se pueden citar tantos bellos versos aislados como de él» ${ }^{2}$. Sin entrar en minúsculos cotejos, creo que, con mayor razón, podemos decir esto de Góngora. $\mathrm{O}$, mejor aún (aunque siempre resultan forzadas las oposiciones totales), destacar que de Quevedo recordamos más la poesía que el verso. De Gón-

1 Muy poco se ha dicho sobre la manera fácil de Góngora, cuando habria tanto que decir..." (ALFONSO REYES, Sabor de Góngora [1928], en Capitulos de literatura española, segunda serie, Méjico, 1945, pág. I60). A propósito de Alfonso Reyes, conviene decir aquí que éste recordó el romancillo de Góngora en uno de sus ‘juegos» poéticos:

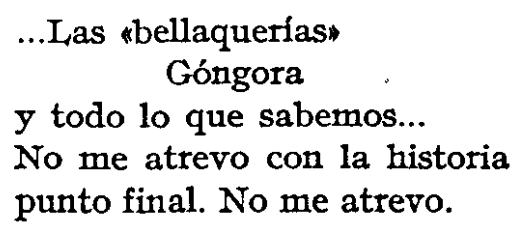

(A. REYES, Minuta, $X X I X$. Sobremesa, en Obra po6tica, ed. de México, 1952, pág. 320).

2 Quintana, Tesoro del Parnaso español, ed. de París. s. a., pág. 27. 
gora, más, quizá, el verso que la poesía. Pero son tantos los versos inolvidables de Góngora, que llegamos a constituir una especial antología que - me parece- no tiene par en la lírica española ${ }^{1}$.

Dejemos ya los preliminares y entremos en materia. El verso (y metáfora) que me interesa es el que aparece a poco de comenzar las Soledades:

Era del año la estación florida en que el mentido robador de Europa -media luna las armas de su frente, y el sol todos los rayos de su pelo--, luciente honor del cielo, en carmpos de zafiro pace estrellas...

Detengámonos en el último verso:.. en campos de zafiro pace estrellas... Naturalmente, es uno de los versos que forman parte de esa especial antología gongorina $\mathrm{y}$, al mismo tiempo, de los que han determinado más frecuentes - y encontrados- estudios de fuentes. Con otras palabras, es un verso con historia propia, aparte de la merecida fama que lo envuelve.

Digamos, en primer lugar, que este verso corresponde a una segunda -y definitiva - versión de las Soledades. En la primera versión figuraba de esta manera:

en dehesas azules pace estrellas... 2 .

Un rápido cotejo de las dos versiones nos permite comprender, aun en el análisis elemental, el proceso intensificativo metaforizador de Góngora, al transformar un color directo en una nueva metáfora.

Verdad es que la metáfora fundamental del verso (el (pace estrellas") se reduce en Góngora a este único ejemplo, a pesar de las sospechas de

1 Hay también poetas de excelentes versos aislados y malas poesias. Aparte de que éste no es nuestro caso, creo que la relación normal es la previsible: los buenos versos están por lo común en los buenos poemas. Existe, además, el caso (como nos muestra alguna antologia francesa) de poetas que deben su supervivencia a un único y breve poema ( $y$, a veces, a un verso). Todo es posible en el camino ancho de la poesia...

- Esta forma está atestiguada por Francisco del Villar (ver CASCALES, Cartas filológicas) y por el ABATE DE RUTE (Examen del Antídoto, de JAUREGUT). Ver M. RODRTGUES LAPA, Uma versão desconhecida da I." "Soledad" de Góngora. Lisboa, I935, pág. 8. Rodrigues Lapa publica un manuscrito conservado en la Biblioteca Nacional de Lisboa, que corresponde a la primera o una de las primeras versiones de casi toda la Soledad primera (ro34 versos). Esa versión conserva la primera forma del verso que nos interesa: ...ken dehezas azules pace strellas..." (página II). 
Alfonso Reyes (y, antes, Angulo y Pulgar) acerca del prólogo de La gloria de Niquea, comedia de Villamediana ${ }^{1}$. En ese prólogo están los versos:

El que ves, toro, no en las selvas nace

a mis floridos yugos obedientes:

en campos de zafiro estrellas pace...

Hoy se acepta más bien -a través de Dámaso Alonso- que sólo se trata, como era frecuente en Villamediana, de uno de los tantos aprovechamientos de versos enteros de Góngora ${ }^{2}$. En fin, el verso sen campos de zafiro estrellas pace» de dicho prólogo sería un verso de Góngora, pero fuera de Góngora. De todos modos, nítidamente centrado en la órbita del poeta cordobés.

Quedémonos en Góngora. Estableciendo una derivación muy explicable dentro del mundo que el poeta va construyendo (mundo con relaciones, ampliaciones y ramificaciones), es muy posible que el upacer estrellas» haya nacido de su propio «pisar estrellas»:

...ver a Dios, vestir luz, pisar estrella...(En una fiesta que se hizo en Sevilla a San Hermenegildo. I590.)

Deja el monte, garzón; poco el luciente venablo en Ida aprovechó al mozuelo, que estrellas pisa ahora en vez de flores... (Soneto. $A$ un hijo del Marqués de Ayamonte... 1607.) ...rayos ciñe de luz, estrellas pisa. (Soneto, Al Conde de Lemus... ...darán número a las flores I609.)

cuando no písen estrellas. (Comedia. El Doctor Carlino, r613.)

$\mathrm{Y}$ aun pasa la época de las Soledades:

...de los que, a un campo de oro cinco estrellas dejando azules, con mejores plantas en campo azul estrellas pisan de oro. (Soneto. De la Capilla de Nuesira Señora del Sagrario, $\left.16 \mathrm{I}^{2}\right)^{3}$.

1 Cf. Alfronso REYes, Cuestiones gongorinas, Madrid, 1927, pág. 31. La gloria de Niquea fue una comedia escrita por el conde de Villamediana, amigo y discípulo de Góngora. Góngora escribió una décima en elogio de la comedia, ver GÓNGORA, Obras poéticas, III, Nueva York, I921, pág. 37.

2 Cf. DÁmaso Alonso, Crédito atribuible al gongorista don Martin de Angulo y Pulgar, en Estudios y ensayos gongorinos, Madrid, 1955, págs. 415-439.

3 M. de Montoliu cita, traducido al español, un verso de Marino como anticipo del verso gongorino. El verso de Marino es el siguiente:

El sol que pace un forraje de estrellas... 
Agreguemos, en fin, dentro de un explicable juego de relaciones y sin establecer ya prioridades, expresiones como upisa el viento (Canción. ¡Qué de invidiosos montes levantados... r6oo; upor mis trazas pisa el vienton. (El doctor Carlino, I6r3); "pisando la dudosa luz del dia (Polifemo, verso 72); "...el eclíptico zafiro/pisar quería..." (Soledad primera, versos 7I8-7I9);" "...que zafiros pisa..." (Soneto. En la muerte de una dama portuguesa..., I62I); "Pisó el Zenit..." (Panegírico, verso 497).

Esta confluencia y fecundidad (junto con la frectuencia con que aparece) personaliza el juego de relaciones y da singularidad a la metáfora - metáforas gongorinas. Deteniéndonos en la indudable relación fonética entre pisar y pacer, ¿qué valor tiene la fácil referencia al virgiliano «Polus dum sidera pascet...?" (Eneida, I, I).

En primer lugar, no se trata exactamente de la metáfora de Góngora, como ligeramente ha sostenido Justo García Soriano ${ }^{1}$, preocupado más en señalar «hurtos» y en arañar versos del cordobés que en comprenderlo. Posteriormente, Arturo Marasso, si bien piensa también en Virgilio, a través de Pellicer ${ }^{2}$, no establece una derivación tan estricta. Por último, Jorge Luis Borges, al comparar un verso de Dante «... Dolce color d'oriental zaffiro..." (Purgatorio, I, I3), y el verso de Góngora, dice de manera rotunda: "Ambos versos derivan de la Escritura"; "Y vieron al Dios de Israel; y había debajo de sus pies como un embaldosado de zafiro, semejante al cielo cuando está sereno" (Exodo, 24; ro) ${ }^{3}$. Por lo pronto (y sin considerar el adivinable veredicto de Borges acerca del valor de los versos), resulta aventurado decir que el verso de Góngora deriva de la Escri-

Ver M. DE MONToxfu, Literatura castellana. Barcelona, 1937, pág. 308. Agrega otras consideraciones para probar que el gongorismo deriva del marinismo. Aduce como una de las pruebas fundamentales la publicación de las Rime de Marino, en I602. Como el gongorismo (está hoy probado de sobra) es muy anterior a I602 se debilita considerablemente la afirmación del critico.

1. Cf. Justo García Soriano, notas a Cascalies. Cartas filológicas, I, ed. de Madrid, I930, pág. I99.

2 Ver ARTuro MARAsso, Una nota sobre las Soledades de Góngora, en el Boletín de la Academia Argentina de Letras. Buenos Aires, 1936, IV, núm. 15, págs. 425-427. Marasso cita también un verso de Lucrecio:

...et solis flamman per caeli Caerula pasci...

Cf., también, A. Marasso, Luis de Góngora, en Góngora. Obras completas, ed. de Buenos Aires, 1955, pág. 17.

3 J. L. BORGES, La metáfora, en La Nación, de Buenos Aires, 9 de noviembre de 1952, reproducido en Historia de la Eternidad. Buenos Aires, 1953, pág. 74. Creo, en fin (y contra el juicio de Borges), que el verso de Góngora no es runa mera grosería, un mero énfasis». Borges - no lo descubrimos ahora- es un gran escritor 
tura. Sobre todo, si tenemos en cuenta que el acento fundamental dè la metáfora gongorina recae desde un principio en el "pacer estrellas», $y$ no en «cielo»/(zafiro» (que, por otra parte, sabemos corresponde a una segunda versión que no altera lo esencial de la primera).

Volviendo a aquellos siglos, y procurando sentar apoyos valederos, quiero destacar, con cierta amplitud, un verso de Garcilaso. No se ha reparado, que yo sepa, en un verso del famoso poeta de las Eglogas:

Pisa el inmenso y cristalino cielo teniendo puestos de una $y$ otra mano el claro padre y el sublime abuelo. (Garcilaso, Elegia I) ${ }^{\mathbf{1}}$.

verso - «Pisa el inmenso y cristalino cielo»- que, por supuesto, puede aducirse dentro de la relación pisar/pacer que he defendido en Góngora.

Yo creo que, sin romper hilos sutiles que ligan a Góngora con poetas anteriores (entre ellos, Virgilio), lo importante es reparar en el valor personal, la reiteración y las combinaciones que adquieren estas metáforas gemelas en sus versos. Razón de poesía que llevaba a Francisco del Villar a proclamar su admiración por el comienzo de las Soledades y, especialmente, por nuestro verso: "Pues bien se toca el punto de astrología; y el pacer estrellas en dehesas azules escríbase con letras de oro..." ${ }^{2}$. (No hace falta aclarar que $F$ rancisco del Villar se refiere a la primera versión.) $Y$ lo que Del Villar decía directamente y con tanto fervor, muchos otros lo dijeron indirectamente a través de versos que partieron - no cabe duda- de bases gongorinas: tanta fijeza tuvieron y con tanto vigor lírico se impusieron a través del poeta cordobés. Como es fácil probar, se acogieron a la lograda metáfora de Góngora («de Góngora», ya con este sello) sus amigos y admiradores, pero no menos los rivales o, simplemente, poetas, grandes poetas, que no podemos contar como gongoristas, aunque a veces (consciente o inconscientemente) gongoricen. Así, Lope:

(obras de ficción, poesías). Pero una vez más la crítica de Borges referida a Góngora revela incomprensión y hostilidad. No se trata, por supuesto, de pretender el elogio bobo, sino de obligar a un más justo análisis. $Y$ aqui la parcialidad resulta evidentísima.

1 Garcilaso y Boscan, Obras poéticas, ed. de Madrid, I9I7, pág. I46.

2 En Francisco Cascales, Cartas filológicas, I, ed. de Madrid, r930, pág. 199. ("Don Francisco del Villar al padre maestro Fray Joan Ortiz, ministro de la Santísima Trinidad en Murcia川). Lo curioso es que Cascales se aproxima también, en un párrafo de su prosa, a la inconfundible metáfora: a...donde han de angelicarse y pisar las estrellas..." (CASCALES, Cartas filológicas, III, ed. de Madrid, I94I, pág. 134.) 
Por los campos del cielo desatado paciendo estrellas... ( $L a$ Andrómeda) ${ }^{1}$.

Diez veces nuestra argolica milicia sobre Troya miró flechando a Croto y otras tantas el Toro de Fenicia pacer estrellas al celeste soto... (La Circe) ?

Quevedo:

Merecen pacer estrellas en turquesado pesebre, que el Vellocino de Colcos dé terliz a sus jaeces... (El Parnaso español, II, pág. I29)

Traigo el campo que pacen estrellado las fieras altas de la piel luciente. (Id., I, pág. 280.) Un animal a la labor nacido

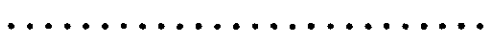
y rumia luz en campos celestiales. (Epistola satirica y censoria) . No dudo que tu pie, en el coro santo, pise estrellas, si estrella en él no fueres. (El Parnaso español. I, pág. I 5o.)

Estrellas pisa, estrellas enamora. (Id., III, pág. 394.)

Medrano:

Ya, Ya, soberbios astros, vuestro cielo Flora pisa inmortal con firmes huellas; ya, eternamente hermosa, pisa estrellas. (Soneto) ${ }^{\mathrm{s}}$.

Tirso:

[Don Juan] La noche en negro silencio se extiende, y ya las cabrillas entre racimos de estrellas el polo más alto pisa. (El burlador de Sevilla...) '.

1 LOPE DE VeGA, La Filomena. Madrid, r62r. Cit. por Justo Garcia SoRIANO, nota a CASCALES. Cartas filológicas, I, pág. 207.

2 Biblioteca de Autores Españoles, XVIII. Madrid, 1908, pág. 500. El poeta argentino Ricardo E. Molinari cita como epigrafe en uno de sus libros estos versos de Lope:

En el sereno campo-de los cielos entraba el sol, pisando las estrellas.

Ver El huésped y la melancolia. Buenos Aires, 1946, pág. 46.

- QUEVEDo, El Parnaso español, tres tomos. Zaragoza, I886.

4 Verso, el último, atacado por QuiNTaNa: "Góngora no deliraría másn, dice. Ver QUINTANA, Tesoro, pág. 355. Lo curioso es que el verso tiene raigambre gongorina.

- Francisco DE MEDRANo. Soneto XII. Ver DAmaso Alonso, Vida y obra de Medrano, I, Madrid, 1948, pág. Ioo.

- TIRso De Molina, El burlador de Sevilla (acto III), ed. de Madrid, I932. página 256. 
Bocángel:

Era la noche, en que el león del cielo rugiendo en campos de zafir flamante. (Retrato panegirico del Infante don Carlos) '.

Como al partir del sol la sombra nace, monstruo de hielo, y sombra fabricado, que en los campos del cielo estrellas pace. (Elegia a la muerte de Lope de Vega) ${ }^{2}$.

En fin, hasta en la sátira del Estebanillo González:

...que dejando en Madrid reliquias bellas al cielo se partió a pisar estrellas... ${ }^{3}$.

Pasando el Océano, veamos ejemplos americanos. Pedro de Oña:

...mientras al sol de gloria soberana, veloz, pisando estrellas, va doña Ana. (El Vasauro) 4. Cual grama el bruto, viento el hombre pace. (El Vasauro) 5 .

Sigüenza y Góngora:

¡Oh, tú, que en tronos de diamantes puros, pisando estrellas, vistes del sol rayos!... (Primavera indiana) ${ }^{6}$.

Domínguez Camargo:

Cuando el sol crespa luz viste al cordero, que en la dehesa azul, flores de estrellas pace retozador. (Poema heroico...) ?

Espinosa Medrano cita así el verso de Góngora:

Que en campos de zafiro estrellas pace... (Pane girica declamación por la protección de las ciencias $y$ estudios...) 8 .

1 BoCÁNGEr, Obras, I, ed. de Madrid, r946, pág. 193.

2 BocÁNGEL, La liva de las musas... Madrid, 1637, pág. 28.

3 Vida y hechos de Estebanillo González, II, cap. XV; ver texto en La novela picaresca española, ed. de Madrid, 1947, pág. I827. Agrego, aquí, Pedro Fispinosa, Panegivico al duque de Medina Sidonia, en Obras, ed. de Madrid, I909, pág. 370.

4 Pedro de OÑa, El Vasauro, ed. de Santiago de Chile, I94I, pág. 270.

- OÑa, El Vasauro, pág. I4I.

- SigüEnza y GÓNGORA, Primavera indiana, verso 45, en Poemas, ed. de Madrid, I93I.

7 Hernando Domínguez Camargo, Poema heroico de San Ignácio de Loyola, Madrid, r666, pág. 356.

8 Biblioteca de Cultura Peruana, El apogeo de la literatura colonial. Paris, 1938, pág. r95. 
que es, en rigor, el verso de La gloria de Niquea, verso que - hemos vistose ha atribuido a Góngora, como posible autor del prólogo de la comedia. El Conde de la Granja:

...entre la verde grama estrellas pacen... (Vida de Santa Rosa) ${ }^{1}$.

Con posterioridad, el verso sigue, en forma paralela, los conocidos albures que sigue el prestigio de Góngora. En épocas en que se ataca a Góngora y se le considera como una aberración ¿qué tiene de raro que desaparezca, prácticamente, la fecundidad de su verso? Sobre todo, tratándose de un verso "gongorino" como el que nos ocupa. Aparece, sí, en la sátira, y esto ya nos indica, a su modo, la nueva etapa. Recuerdo a manera de ejemplo el verso de la Sátira segunda A Arnesto, de Jovellanos.

De la divina Ladvenant que ahora anda en campos de azul paciendo estrellas... ${ }^{2}$.

Donde se persigue, no ciertamente un homenaje al poeta cordobés, sino un efecto de artificiosidad y pura burla.

Por último, siguiendo fielmente esa trayectoria, tampoco nos sorprende que reaparezca (aquí como reconocimiento de belleza y homenaje indudable) en el famoso Trébol de Rubén Darío:

En tanto wpace estrellas" el Pegaso divino... (Soneto tercero) ${ }^{3}$.

Verso donde el homenaje se destaca hasta en las comillas: las únicas que utiliza en los tres sonetos. Señal indirecta de cómo se le había fijado también a Rubén Darío el acierto de este verso muy gongorino y muy logrado.

Después es más difícil encontrarlo. Sin embargo, doy dos ejemplos que -creo- pueden servir para mostrar una fecunda descendencia, sin necesidad de precisiones, muy difíciles de probar.

1 Conde De IA GRANJA, Vida de Santa Rosa de Santa Maria, Lima, I7II, página 16.

2 Cf: G. M. DE Joveri,ANos, Sátira segunda A Arnesto. Ver LEÓN MEDINA, Frases literarias famosas, en la Revue Hispanique, de Nueva York-Paris, I9II, $\mathrm{XXV}$, pág. 59 .

3 RUBÉN DARío, Trébol, en Cantos de vida y esperanza, ed. de Barcelona-Madrid, 1907, pág. 91. 
...bajo una piel de toro pisa y pace un luminoso prado de toreros. (Miguel Hernández) ${ }^{1}$.

Cielo, déjame un día de estrella a estrella irme pisando luz y pólvora. (Pablo Neruda, Quiero volver al sur) ${ }^{2}$.

En los párrafos precedentes he procurado encerrar, si no la historia, por lo menos jalones en el itinerario de un famoso verso gongorino. Sin negar totalmente una raíz virgiliana (pero tampoco sin darla por incontestable), he pretendido, más bien, mostrarlo originándose dentro del propio mundo poético de Góngora. Contaminación de metáforas a que lleva la proximidad fonética y que — cosa corriente en él-ganan, a su vez, ramificaciones y enriquecimientos. Proceso que, por otra parte, puede explicarse también dentro del espíritu barroco, donde es notorio un límite visible junto a una extraordinaria variedad dentro de ese límite. En el caso de Góngora, con más razón que en otros poetas, asistimos al previsible desarrollo: el poeta va creando su mundo, y, en esa creación, entran materiales nuevos y ajenos, pero no menos aquellos que derivan de lo ya hecho por el poeta y que configuran "su» mundo propio. Eso es -me parece- lo que ocurre con el «pace estrellas» y el "pisa estrellas», si bien para nosotros siempre resaltará con luces más encendidas el verso famoso de las Soledades, verso que resume felizmente muchas de las cualidades gongorinas:

...en campos de zafiro pace estrellas...

III

Rey de rios...

Esta expresión nos servirá para mostrar un caso de intemperancia crítica y, al mismo tiempo, la situación de Góngora en el uso de un especial superlativo poético.

En varias ocasiones empleó Góngora la frase «Rey de los otros ríos». En un soneto juvenil llama al Guadalquivir:

Rey de los otros ríos caudaloso ${ }^{3}$, que en fama claro, en ondas cristalino. (Soneto, $\mathrm{x}_{582 .)}$

1 Cf. MrgUer, HeRnÁNDEZ, soneto 28 de El rayo que no cesa, en Obra escogida. Buenos Aires, 1958, pág. I32.

2 PABLo NERUdA. Quiero volver al sur, en Canto general, II, ed. de Buenos Aires, 1955, pág. 22. Agrupo, por último, ejemplos en Gabriela Mistral (Ternura) y en Rafael Alberti (La Gallarda).

3 En otra versión: «Rey de los otros ríos caudaloso...» Este verso fue elogiado entusiastamente por Quintana (si bien éste - sabemos - no dejaba de distinguir entre el Góngora "brillante, ameno y lozano» y el "extravagante y caprichoso"): 
En un romance poco posterior llama de nuevo al Gudalquivir

Th́, rey de los otros rlos, que de las sierras sublimes de Segura al Océano el fértil terreno mides. (Romance. Aqui entre la verde juncia, I584.)

Por tiltimo, en las Soledades el rey es el río Nilo:

...y, vadeando nubes, las espumas del rey corona de los otros ríos: de cuya orilla el viento hereda ahora pequeños, no vacios, de funerales bárbaros trofeos que el Egipto erigio a sus Ptolomeos... (Soledad primera, versos 959-964.)

Quizá por esta reiteración y por el hecho de no encontrarse en España ejemplos anteriores (digo, no se han señalado) pensó Pedro Henríquez Ureña que esta expresión uparece provenir del maestro cordobés» ${ }^{1}$. Hoy sabemos que el punto de partida es virgiliano: "Erídano, rey de los ríos».

Fluviorum Rex Eridanus. (Georgica, I, verso 482) 2.

y que tuvo abundante descendencia en la poesía italiana del Renacimiento. En gran parte, esto lo sabemos a través de Juan de Jáuregui, quien, en el Antidoto contra las Soledades, le reprochaba a Góngora el "error» de

¿ En cuál de ellos se encontrarán periodos poéticos que en riqueza de lenguaje, en lozanía y en número puedan competir con los siguientes

Rey de los otros ríos caudaloso, que en fama claro, en aguas cristalino...

Por supuesto, este ejemplo perteneceria - según Quintana- al primer Góngora (?) Ver Quintana, Tesoro del Parnaso español, ed. de París, s. a., pág. 24.

1 PedRo HeNRqueZ URENA, Notas sobre Pedro Espinosa, en R. F. E., I9r7, IV, pág. 29I.

2 El soneto de Góngora Rey de los otros rios caudaloso... figura en la primera parte de las Flores de poetas ilustres, de PEDRO DE ESPINOSA. Valladolid, 1605. folio 1 $_{4} 6$, b. El ejemplar de la Hispanic Society of New York (famoso ejemplar con historia propia) ofrece estas anotaciones manuscritas de Gallardo:

Tasso, Rim. P. I. a, soneto I8:

Re degli altri superbo altiero fiume.

Petrarca.

Virgilio:

Fluviorum Rex Eridanus. 
usar el particular superlativo fuera de la identificación acuñada por Virgilio (Rey de los ríos=Erídanos=Po), identificación aceptada por los poetas italianos en general.

Repito que no tenemos por qué dudar aquí del origen virgiliano del verso de Góngora. Sabemos, a través de José Pellicer de Salas y Tovar, que el poeta español "era muy aficionado a Virgilio, Claudiano y Horacio» ${ }^{1}$, si bien debe ser cada caso particular el que sirva para atestiguarlo. Aquí -repito- no creo que haya dudas.

Con respecto a los poetas italianos, bueno será citar ejemplos:

Re degli altri, superbo, altiero fiume ch'in contra il Sole. (Petrarca.)

...lasciato avendo lamentar indarno il re de' fiumi, ed invidiarvi ad Ärno. (A viosto.)

o Eridano mio...

$\mathrm{O}$ re de' fiumi, in queste piagge' sole odi le mie parole. (Ariosto.)

Re degli altri, superbo, altiero fiume che qual or esci del tuo regno... (Torcuato Tasso.)

Come degli altri fiumi il re tal volta.. (Torcuato Tasso.)

Con la fronte di toro il re dei fiumi. (Julio Camilo.) ${ }^{2}$.

Para los poetas italianos el «Rey de ríos»es, naturalmente, el Po. Pero Góngora no se refiere el Po, sino al Gudalquivir o al Nilo. Lo curioso es que Jáuregui, ofuscado por su afán de señalarle errores y oscuridades, llega hasta el extremo (poco admisible en quien, como él, era poeta, y alto poeta) de pretender que la expresión poética no debe salir de la acuñación primitiva. En este caso, sin duda, la de Virgilio, que fue tan repetida como clara alusión al Po. «No puede ya nadie -concluía Jáuregui- llamar a otro río "rey de los otros», sino al Po..." ${ }^{3}$. Por supuesto que nada obligaba (ridículo hubiera sido pretenderlo, a pesar de Jáuregui) a encerrar allí la felicidad de la frase. Podía aplicarse a otros ríos y aun

1 José Pelificer de Salas y Tovar, Vida de don Luis de Góngova (vida mayor), en Góngora. Obras poéticas, III, Nueva York, I921, pág. 306.

2 Casi todos los ejemplos son citados precisamente por Jáuregui. Ver JUAN DE JÁUREGUT, Antidoto contra las "Soledades", reproducido en J. JORDÁN DE URRÁS, Biografia y estudio crítico de Jauregui, Madrid, I899, pág. I74. Ver también ARIOSTO, Livica, Bari, I924, págs. 5 y 238; Torcuato Tasso, Opere. IV, Milán, I824, pág. r92.

3 JÁurgGut, Antidoto contra las «Soledades", pág. I74. 
extender la construcción fuera de la órbita fluvial. Buen ejemplo es el de Pietro Bembo que -claro está- no cita Jáuregui:

Re degli altri, superbo e sacro monte. (P. Bembo, Soneto) ${ }^{1}$.

A partir de Góngora, sí, hay en España un uso abundante de la expresión. Lo prueban, de nuevo, sus contemporáneos, $y$, naturalmente, con la libertad que se tomaba Góngora:

Tú, Jordán, rey de ríos, escogido de Dios para que a Dios le des mañana las aguas del bautismo soberano. (Pedro de Espinosa, Al bautismo de Jesus) ${ }^{2}$.

...mas, como amigo, sus riquezas parte con él; que es rey de ríos, y los reyes no dan tributo, sino ponen leyes. (Id., Fábula de Genil) ${ }^{\text {s. }}$

El rey de rós, líquido monarca, de sus arenas Midas cristalino... Tajo (Quevedo, $A$ don Jerónimo de Mata, Epodos) ‘.

Para cuya corona, como a solo rey de los ríos, entreteje $y$ ata Palas su oliva con la rama ingrata que contempla en las márgenes Apolo. (Arguijo, Soneto. Al Guadalguivir en una avenida) ${ }^{5}$.

1 Cf. J. Carduccr, Primavera e fiore della lirica italiana, I, Florencia [Sansoni], s. a., pág. I9o.

2 Ver PEDRO DE ESPINOSA, Obras. ed. de Madrid, 1909, pág. 18.

- Pedro de Espinosa. Obras, pág. 28. (Cf., también, Pedro Henrfquet URENA, Notas sobre Pedro de Espinosa, pág. 29r.)

- QUEVEDo, El Parnaso español, III, ed. de Zaragoza, 1886, pág. 300.

- Lo cita Marínez DE LA Rosa en las Anotaciones a la Poética (ver Obras completas, I, Paris, I845, págs. I43-I44). Martínez de la Rosa lo antecede con estas palabras: "Don Juan de Arguijo, contemporáneo y paisano de Herrera, pudo decir en lenguaje magnifico..... Y más adelante:

-...algunos años después Góngora celebraba al mismo rio con dicción tan noble y sonora como la siguiente:

Rey de los otros rios caudaloso..." (págs. 143-144).

Aclaremos que Arguijo ( ¿ 1567 ? ¿ I 560?-I623) es coetáneo de Góngora (1 561-1627)No me parece que el soneto de Arguijo sea anterior a 1582 (ni aun considerando que pudo nacer en I 560). Quizá parte de ejemplos italianos, pero su soneto es, sin duda, posterior al de Góngora. Además, creo que Arguijo acepta precisamente la identificación macional» que proponía Góngora. 
La fecundidad y descendencia no termina aqui, si bien después se hace -explicablemente- más espaciada ${ }^{1}$.

Resumiendo lo dicho vemos que Góngora, aquí, adapta y da libertad al verso virgiliano, procedimiento que en España es inmediatamente seguido por otros poetas, sea partiendo del poeta latino, sea partiendo de los versos del poeta cordobés (y me inclino por esto último).

En cuanto a la actitud de Jáuregui (él también era alto poeta), la explicamos menos por convicción que por su oposición a Góngora, bien que su poesía se acerque más de una vez a la del absorbente rival ${ }^{2}$. Y no deja, por eso mismo, de tener ribetes contradictorios.

Nos encontramos, así, frente a un nuevo ejemplo que muestra los extravios a que conduce el apasionamiento y el recelo personal, que tanto suelen pesar en las polémicas literarias del siglo xvII (y de todos los tiempos) aun en los mejores poetas. E1 limitado caso de Jáuregui no es, en su carácter, el único que podemos traer hasta estas páginas. Sin la pretensión de un paralelismo absoluto, recuerdo también que Quevedo se burlaba en La Perinola de un verso - de vago cuño gongorista- que usaba Montalbán:

...corriendo en poco salto tierra mucha...

1 Ver, en el siglo $\mathbf{x I x}$, al venezolano (español) Baralt, que tamericaniza la expresion:

Alli, raudo, espumoso,

rey de los otros rios, se arrebata

Marañón caudaloso

con crespas ondas de luciente plata,

$y$ en el seno de Atlante se dilata...

(Oda a Crsitóbal Colón en El Araucano, de Santiago de Chile, 19 de noviembre de 1850 , pág. 4).

Claro que no pueden extrañarnos en Baralt tales reminiscencias, ya que era hombre de lecturas poco comunes en su tiempo. En mi libro El gongorismo en América, Buenos Aires, 1946, págs. 215-218, he procurado mostrar, sobre todo, aprovechamientos cultistas (nunca exagerados) en poetas como Bello y Baralt.

2 Cf. Gerardo DIEGo, Antologia poética en honor de Góngora, Madrid, 1927, páginas 36-37 y 125-128. JOSE JORDÁN DE URRIES, en su Biografia y estudio critico de Jáuregui, Madrid, I899, pág. 39, cita dos poesías anónimas dirigidas contra Jáuregui, en las cuales se le reprocha la contradicción que supone atacar al cultismo $y$, por otra parte, escribir "culto".

\section{Pecador en lo mismo que predicas...}

dice uno de los versos de las poesias. 
Lo que no le impedía a Quevedo escribir, en una de sus poesías de El Parnaso Español:

....mucha muerte en poco plomo... ${ }^{1}$.

Góngora, gongorizar

Damos por bien sabida la elemental noticia: don Luis de Góngora y Argote era, en realidad, Góngora por su madre, y Argote por su padre. No sé si, como dice Millé y Giménez, «complicaciones nobiliarias y conveniencias económicas, muy frecuentes en aquel tiempo, lleváronle a preferir el apellido materno, aunque el paterno era también muy ilustre» ${ }^{2}$. Lo que sí sé (aquí tenemos una prueba) es que el orden de los apellidos no era entonces tan riguroso como hoy ${ }^{3}$. De tal manera, los contemporáneos y la posteridad lo conocieron como "Góngora»: nombre muy de acuerdo con esenciales resonancias de su poesía. (Otra curiosidad, o, más bien, coincidencia, podemos agregar: Góngora y Córdoba.)

En las letras en lengua española hay otros casos recordables en cuanto a nombres (Rubén Darío, Valle Inclán, entre varios), pero ninguno nos llega con la rotunda sonoridad y brevedad del de Góngora. Por supuesto que no pretendo ocuparme de algo tan conocido como es el nombre del poeta, sino de los derivados que discípulos, admiradores, rivales, lectores, críticos, etc., sacaron de ese nombre-base, nombre de posibilidades poco comunes.

Es indudable que la función crea la palabra. E1 eufónico nombre de Góngora -claro está- ayuda, pero no se trata sólo del nombre en sí, sino de una necesidad de nominación para expresar usos nuevos. Nacieron, así, derivados como gongorismo, gongorista y gongorino, de uso

1 Ver QUevedo, El Parnaso español, II, pág. 355.

2 JUAN MILLế Y GINÉNEZ, Biogratía de don Luis de Góngora, en GÓNGORA, Obras completas, Madrid, I943, pág. XXVII. Podemos recordar, en tales intríngulis, a su tío Francisco de Góngora y a la "ración» de la catedral de Córdoba.

3 Cf. Dámaso Aronso, Góngora y El Polifemo, I, Madrid, 196r, pág. 35. Don I uis de Góngora tuvo un hermano llamado Juan ¿Juan de Argote? ¿Juan de Góngora? En un Escrutinio sobre las impresiones de las obras poeticas de don Luis de Góngora (publicado por MILLE y GIMÉNEZ), el escrutador no acepta que el final de Las firmezas de Isabela sea obra de "Don Juan de Argote, su hermano». Y añade que "su hermano de don Luis se llamó don Juan de Góngora, apellido por el cual se conoció, y no por el de Argote..." (ver GónGORA, Obras completas, pág. I134). 
frecuentísimo; el verbo gongorizar, explicablemente, mucho más utilizado en los siglos xvII y xvIII que hoy; y aún vocablos menos corrientes que parten del ancho nombre propio: gongórico, gongoriano, gongoresco, gongorano, gongorizado, desgongorizado, gongorinamente, gongorófobo... (Y no hablemos de aquellos que, con limitada extensión de burla, nacieron de la sátira de Quevedo: Gongorilla, desengongorarla, jeri(n)góngora) ${ }^{1}$.

Según Romera Navarro, Miguel Colodrero de Villalobos, discípulo de Góngora, fue uno de los primeros en usar el verbo gongorizar ${ }^{2}$. Otros ejemplos:

....al baile van Olallas, Blases, Giles, trovas cantan, no cultas por extrañas, que allá no se autorizan los que al uso de agora gongorizan. (Tirso de Molina) ${ }^{3}$.

Sblo uno en el mundo gongoriza. (Pedro de Espinosa) 4

...gongorizar con elegancia campanuda. (Estebanillo Gonzilez) ${ }^{5}$.

1 Gongorilla, Gongorilla, de parte de Dios te mando... (Quevedo, Poeta de ;Oh qué lindico!, I614.)

Yo te untaré mis versos con tocino, porque no me los roas, Gongorilla... (Quevedo, Soneto, I609.)

Alguacil del Parnaso, 'Gongorilla.. (Quevedo, I62 I.)

Ver QUEVEDo, Obras. Verso, ed. de Madrid, I943, págs. I48, I 47 y I5o.

...que para perfumarla

y desengongorarla

de vapores $\tan$ crasos,

quemo como pastillas Garcilasos. (Quevedo, i1625?)

Estos versos corresponden a la poesía que comienza Alguacil del Parnaso, Gongorilla (Id., pág. I52).

...éste a la jerigonza quitó el nombre,

pues después que escribió cíclopemente,

la llama jerigóngora la gente. (Quevedo, Este que en negra tumba, id., pág. I52.)

S6́lo como curiosidad podemos recordar aquí los nombres lanzados contra Lope: Lopillo, Lopico \& Lopa.

2 Citado por M. Romera NAvARRo, La preceptiva dramática de Lope de Vega, Madrid, I935, pág. 270.

3 TIRSO DE MOLINA, Deleitar aprovechando, Madrid, 1935, fol. 82. Ver, también, la comedia Santo y sastre (I, $\mathrm{x}$ ).

- PEDRO DE ESPINOSA, El perro y la calentura, en Obras, ed. de Madrid, I909, pág. I8I.

s Vida y hechos de Estebanillo González, II, cap. VI, en La novela picaresca española, Madrid, 1946, pág. I833. 
... por gongorizar, en la maleta

del cordobés poeta

meti las uñas, y en las Soledades

acometi mil hurtos y maldades. (Polo de Medina) ${ }^{1}$.

Iin fin, en otro grupo:

(iQué gongórico que estoy!) (Antonio de Mendoza) 2.

...Don Martin de Angulo y Pulgar, que llevó su idolatría gongórica al extremo de hacer centones de las obras de su maestro. (Menéndez y Pelayo) ${ }^{3}$.

De lo gongórico en la poesia peruana actual (Raúl Maria Pereyra) 4.

He aqui algunas muestras de esos juicios gongorófogos... (Américo Castro) ${ }^{5}$.

...allá no se ha acabado de beber en las más diversas fuentes clásicas, folklóricas, gongorianas, orientales... (Dulce Maria Loynaz) $\cdot$.

...era uno de los numerosos opúsculos gongoranos escritos por el padre Orellana: Las amenas florecillas de la Virgen del Valle... (Manuel Soria) ?.

$O$ en Rafael Alberti, hoy completamente desgongorizado.. (Ildefonso Pereda Valdés) ${ }^{8}$.

Gongorinamente, te diré que eres noche de claro día vestido. (Manuel Machado) $\bullet$.

1 PoLo DE MEDINA, Obras, en Biblioteca de Autores Españoles, XLII. Madrid, 1906, pág. 184; id.; Obras escogidas, Madrid, I931, pág. 79.

2 ANTonio DE MENDOzA, El Fénix Castellano, Lisboa, I69o, pág. 86. Cit. por Francisco RodrfGuez Marín, Dos mil quinientas voces, Madrid, r922, pág. I88.

- MenÉndez y Perayo, Historia de las ideas estéticas en España, III, ed. de Madrid, I9zo, pág. $4^{8} 7$.

- Título de un estudio de RAúl, Marfa PEREYRA, publicado en la revista 3. de Lima, 1939, núm. 3 .

- Amárico Castro, Volviendo a Góngora, en La Nación, de Buenos Aires, 17 de abril de 1927 .

- Dulce Marfa Loynaz, Ausencia y presencia de Julián del Casal, en Anales de la Academia Nacional de Artes y Letras, de La Habana, I954-r958. XXXVIrI, pág. II3.

7 MANUEl SORIA, Una ayentura de Payró, reproducida por RoBerto J. PAYRó, En las tierras de Inti, ed. de Buenos Aires, 1960, pág. I46.

8 ILDEFONSO PEREDA VAIDÉS, Guia de lecturas de autores clásicos y modernos, I. 2 parte, Montevideo, I936, pág. 460. Cf. la burla de Quevedo "desengongorarla*.

- Manuel Machado. No puedo, ahora, precisar la cita. 
Repito: en esta fecundidad no podemos negar las posibilidades sonoras de un nombre - Góngora-, pero, con más razón, determinan las derivaciones azares vinculados a la obra, a la admiración que despierta y también a la oposición que levanta. Comparativamente, ni Cervantes, ni Lope, ni Quevedo, ofrecen tanta variedad y abundancia, si bien el Diccionario de la Academia, bastante fiel en el caso de Cervantes, se nos muestra mezquino con la riqueza de Góngora ${ }^{1}$.

Por cierto, pues, que la abundancia y variedad, en el caso de Góngora, están indicando que detrás de su nombre y obra se está moviendo todo un mundo de resonancias, de aproximaciones y diferencias, mundo que hoy aparece muy lejos de agotarse. Por lo tanto, no se trata aquí de una simple estadística de nombres muertos, sino de una, casi siempre, imprescindible lista de vocablos. La señal, en la palabra nominadora, de un poeta y una corriente que mantienen a lo largo de los siglos (adhesiones y rechazos incluidos) vigor suficiente como para infundir vitalidad a tales nombres.

Concluyo. Como no hay otro ejemplo semejante en las letras españolas, es justo observar que también aqui, en zonas que no tocan aspectos esenciales de la obra de Góngora, el poeta ostenta una situación de singularidad acorde con prácticamente todo lo que se liga a su eufónico nombre.

EMILIO CARILIA.

1 El Diccionario de la Academia (1947) registra las siguientes voces: Gongorino, na. Que adolece de los vicios [?] del gongorismo./2. Que incurre en ellos. U. t. c. s.

Gongorismo (de Góngora, poeta insigne, príncipe de los culteranos). m. Culteranismo.

Gongorizar. Escribir o hablar en estilo gongorino. 